\title{
Marine Processing Waste - In Search of Bioactive Molecules
}

\section{Hafiz Ansar Rasul Suleria ${ }^{1,2 *}$}

${ }^{1}$ Translational Research Institute, School of Medicine, The University of Queensland, Woolloongabba, QLD, Australia ${ }^{2}$ CSIRO Agriculture, St. Lucia, QLD, Australia

Marine organisms are increasingly being investigated as sources of bioactive molecules with therapeutic applications as nutraceuticals and pharmaceuticals. Marine organisms include sponges, tunicates, bryozoans, molluscs, bacteria, cyanobacteria, macroalgae and microalgae have produced a variety of bioactive molecules targeted to the treatment of a range of infectious and non-infectious diseases [1]. More than 650 new bioactive molecules have been isolated from marine organisms including phytoplankton, green, brown and red algae, sponges, coelenterates, bryozoans, tunicates, echinoderms and molluscs [2]. Extracts or bioactive molecules isolated from these organisms are known to include anti-bacterial, anti-viral, anthelmintic, anti-fungal, anti-hypertensive, anti-cancer and have immune modulatory properties. In particular, retrieval and characterisation of these bioactive molecules from marine processing waste contribute valuable information to the vast field of marine natural product discovery [3].

During marine processing, large amounts of viscera, primarily gonads and digestive tract, are discarded as by-products. This waste is comprised of polysaccharides, proteins, fatty acids, vitamin and minerals that provide a variety of health benefits and could potentially be used as ingredients in functional foods and nutraceuticals, and provide candidates for drug discovery and pharmaceutical development [4]. The successful isolation of bioactive molecules from processing wastes will not only provide new sources of ingredients and candidates for drug discovery, but will also help to find a use for processing wastes that are normally discarded as land fill, helping to reduce the burden on the environment whilst providing industry with ways to add value to their waste streams and decrease waste disposal expenses [5].
Characterisation of these processing waste has revealed bioactive molecules can be used in various industrial applications also for value added products [6]. However, characterisation of bioactive molecules is one of the biggest challenges for researchers in this field because of the structural complexity of e moieties. Therefore, in order to better investigate the structure and composition of these bioactive molecules, innovative cutting edge techniques are required. These will provide information about the types and relative amounts of atoms, the specific environments of atoms within a molecule, the purity and composition, detailed structural information about the molecule, including constitutional and conformational isomerisation. This information will help to further elucidate the mechanisms involved in various biological activities better defining these molecules as potential therapeutics.

\section{References}

1. Kim SK, Pallela R (2012) Medicinal foods from marine animals: current status and prospects. Advances in food and nutrition research 65: 1-9.

2. Blunt JW, Copp BR, Munro MHG, Northcote PT, Prinsep MR (2005) Marine natural products. Natural Product Reports 22: 15-61.

3. Suleria HAR, Osborne S, Masci P, Gobe G (2015) Marine-Based Nutraceuticals: An Innovative Trend in the Food and Supplement Industries. Marine Drugs 13 6336-6351.

4. Suleria HAR, Masci P Gobe G, Osborne S (2016) Current and potential uses of bioactive molecules from marine processing waste. Journal of the Science of Food and Agriculture. 96: 1064-1067.

5. Harnedy PA, FitzGerald RJ (2012) Bioactive peptides from marine processing waste and shellfish: A review. Journal of Functional Foods 4: 6-24.

6. Alishahi A (2012) Chitosan: A Bioactive Polysaccharide in Marine-Based Foods. Biochemistry, Genetics and Molecular Biology "The Complex World of Polysaccharides".
*Corresponding author: Hafiz Ansar Rasul Suleria, RHD Fellow (Food and Nutrition), Translational Research Institute, UQ School of Medicine, The University of Queensland, Kent Street, Woolloongabba, QLD 4102, Australia, Tel: +61470439670; E-mail: hafiz.suleria@uqconnect.edu.au

Received November 05, 2016; Accepted November 07, 2016; Published November 11, 2016

Citation: Suleria HAR (2016) Marine Processing Waste - In Search of Bioactive Molecules. Nat Prod Chem Res 4: e118. doi: 10.4172/2329-6836.1000e118

Copyright: @ 2016 Suleria HAR. This is an open-access article distributed under the terms of the Creative Commons Attribution License, which permits unrestricted use, distribution, and reproduction in any medium, provided the original author and source are credited. 